\title{
Differential Reinforcing Effects of Cocaine and GBR-12909: Biochemical Evidence for Divergent Neuroadaptive Changes in the Mesolimbic Dopaminergic System
}

\author{
Srihari R. Tella,, ${ }^{1,2}$ Bruce Ladenheim, ${ }^{3}$ Anne M. Andrews, ${ }^{4}$ Steven R. Goldberg, ${ }^{1,2}$ and Jean Lud Cadet ${ }^{3}$ \\ ${ }^{1}$ Department of Pharmacology, Georgetown University School of Medicine, Washington, DC 20007, ${ }^{2 B e h a v i o r a l ~}$ \\ Pharmacology and Genetics Section and ${ }^{3}$ Molecular Neuropsychiatry Section, National Institutes of Health/National \\ Institute on Drug Abuse, Division of Intramural Research, Baltimore, Maryland 21224, and ${ }^{4}$ Laboratory of Clinical Science, \\ National Institute of Mental Health, Bethesda, Maryland 20892
}

The dopamine (DA) transporter is thought to be the primary mediator of reinforcing effects of cocaine. In the present study, an intravenous drug self-administration procedure, in vitro autoradiography, and HPLC methods were used to investigate possible differences in reinforcing and neuroadaptive responses to cocaine versus GBR-12909, a selective inhibitor of the DA transporter with a postulated therapeutic use in cocaine abuse. Drug-naive rats readily acquired and subsequently maintained cocaine self-administration behavior during $2 \mathrm{hr}$ daily sessions over a prolonged period. In contrast, although GBR-12909 was initially selfadministered, both cocaine-naive and cocaine-trained rats failed to maintain self-administration behavior for GBR12909 over prolonged periods of time. After selfadministration responding decreased with GBR-12909, rats showed a delay of $6.6 \pm 1.3$ sessions in reacquiring consistent cocaine self-administration. Moreover, when GBR12909 was again substituted for cocaine, they failed to self-administer GBR-12909, even during the initial days of testing. In contrast, after extinction of self-administration responding by water substitution, rats readily self- administered both cocaine and GBR-12909. Cocaine selfadministration upregulated DA transporters, whereas watersubstituted cocaine withdrawal upregulated both DA transporters and D1 receptors. Unlike cocaine, GBR-12909 self-administration by itself altered neither DA transporters nor D1 or D2 receptors. Nevertheless, substitution of GBR12909 for cocaine reversed the cocaine-induced upregulation of DA transporters and reduced DA and dihydroxyphenylacetic acid levels in the mesolimbic system. These data suggest that cocaine and GBR-12909 differentially affect dopaminergic systems and also cause different reinforcing and neuroadaptive effects. GBR-12909-like compounds may be useful pharmacotherapeutic agents for cocaine addiction. Upregulation of DA transporters and D1 receptors might play important roles in the neuroadaptive cascade that leads to cocaine addiction and withdrawal.

Key words: cocaine; GBR-12909; self-administration; reinforcing effects; neuroadaptation; dopamine receptors; dopamine transporters; dopamine; drug addiction; drug withdrawal
A preponderance of experimental evidence indicates that the reinforcing and behavioral effects of cocaine are attributable to its ability to bind to dopamine (DA) transporters and thereby inhibit the reuptake of DA into DA terminals in the mesocorticolimbic system (Johanson and Fischman, 1989; Kuhar et al., 1991; Koob, 1992). Major efforts to develop treatment approaches have focused on this DA hypothesis. One possible therapeutic approach would be to develop a drug that binds to DA transporters but has only small or subtle pharmacological and pharmacodynamic differences from cocaine. Such a drug needs to have very low abuse liability. In this context, recent findings suggesting the possibility of multiple binding domains for inhibitors and substrates of DA transporters (Johnson et al., 1992; Kitayama et al., 1992; Dersch et al., 1994; Giros et al.,

Received July 18, 1996; revised Sept. 9, 1996; accepted Sept. 12, 1996.

This work was supported in part by U.S. Public Health Service Grant DA08830 (S.R.T.) and in part by the Intramural Research Program of the National Institute on Drug Abuse. We thank Ms. Marsha Rosenberg and Dr. H. Hirata for their assistance in autoradiography experiments.

Correspondence should be addressed to Srihari R. Tella, Department of Pharmacology, Georgetown University School of Medicine, 3900 Reservoir Road NW, Washington, DC 20007-2195.

Copyright (C) 1996 Society for Neuroscience $0270-6474 / 96 / 167416-12 \$ 05.00 / 0$
1994; Rothman et al., 1994) (but see Reith et al., 1992) have provided additional impetus for this approach (for discussion, see Rothman and Glowa, 1995). It remains to be investigated whether these multiple binding domains could be exploited for developing treatment drugs for cocaine addiction.

The pharmacological differences between cocaine and piperazine derivatives, namely GBR-12909 and its analogs, have been widely documented. Binding assays using homogenate (Grilli et al., 1988; Refahi-Lyamani et al., 1995) or autoradiography methods (Wilson et al., 1994), microdialysis (Rothman et al., 1991; Baumann et al., 1994), as well as behavioral studies (Rothman et al., 1991, 1992; Katz et al., 1993; Elmer et al., 1996), have all shown differences between cocaine and these drugs. However, some drug-discrimination (Melia and Spealman, 1991; Witkin et al., 1991) and intravenous drug self-administration (Bergman et al., 1989; Howell and Byrd, 1991; Roberts, 1993) studies have suggested that GBR-12909 may be indistinguishable from cocaine. For example, intravenous drug self-administration studies showing that animals will reliably self-administer GBR-12909 when it is substituted for cocaine in cocaine-trained animals (Bergman et al., 1989; Howell and Byrd, 1991; Roberts, 1993) suggest that GBR-12909 may be cocaine-like with regard to its 
abuse potential. It should be noted, however, that these selfadministration studies were performed using procedures that involved substitution of GBR-12909 for cocaine for short time periods. Because short-term substitution procedures do not necessarily reveal the differences in the magnitudes of reinforcing effects of drugs (Johanson and Fischman, 1989), studies using different testing protocols or methods may reveal differences in the reinforcing effects of cocaine versus GBR-12909.

Extensive efforts are being made to understand the behavioral, physiological, and molecular events that occur after chronic exposure to cocaine. There is an underlying assumption that the neurobiological changes mediating drug addiction manifest gradually with repeated exposure (Nestler, 1994). Elucidation of the adaptive changes secondary to repeated exposure to cocaine may also be useful target indices in the evaluation of potential treatment drugs for cocaine addiction. There seems to be a general agreement that repeated exposure to cocaine causes sensitization to its locomotor and DA releasing (Robinson and Becker, 1986; Kalivas and Stewart, 1991) effects and alters electrophysiological effects of DA neurons in the ventral tegmental area (VTA) and their targets in the nucleus accumbens (Acb) (Henry and White, 1991, 1995). However, several studies addressing the changes in pre- and postsynaptic markers for the dopaminergic system have led to conflicting conclusions. For example, DA transporter densities or function have been shown to be either decreased (Izenwasser and Cox, 1990; Sharpe et al., 1991; Farfel et al., 1992; Pilotte et al., 1994), increased (Wamsley and Alburges, 1993; Wilson et al., 1994; Claye et al., 1995), or unaltered (Peris et al., 1990; Yi and Johnson, 1990) after repeated exposure to cocaine. Studies on changes in D1 receptors after repeated cocaine exposure have also been inconsistent, with reports of either no change (Peris et al., 1990; Claye et al., 1995) or increases in the striatum (Wamsley and Alburges, 1993; Unterwald et al., 1994). Similarly, repeated cocaine administration has been associated with increases (Peris et al., 1990), decreases (Spyraki and Sealfon, 1993), or no change (Wamsley and Alburges, 1993; King et al., 1994; Claye et al., 1995) in D2 receptors. These conflicting data could be attributable to the different dose regimens, withdrawal times, and routes of administration used in these studies. Further, these studies primarily involved cocaine administered by the investigator. In this context, it is important to note that substantial pharmacological differences can exist in subjects receiving responsecontingent versus noncontingent presentation of drugs (Siegel, 1988; Ator and Griffith, 1992; Dworkin et al., 1995). Pharmacological agents such as cocaine and nicotine, depending on the context in which they were delivered, can serve as positive reinforcers, negative reinforcers, or punishers (Goldberg and Spealman, 1982; Ettenberg and Geist, 1991). These diverse affective responses could potentially lead to qualitatively different neuroadaptive changes. In light of these, the characterization of neuroadaptive changes in animals after prolonged periods of intravenous drug self-administration will be of greater clinical significance, because this experimental procedure has many similarities with cocaine abuse pattern in humans (Deneau et al., 1969; Johanson and Balster, 1978; Griffith et al., 1980)

The present experiments were designed (1) to investigate whether there are differences in the reinforcing and neuroadaptive effects of cocaine versus GBR-12909, and (2) to examine whether GBR-12909 attenuates cocaine's reinforcing and neuroadaptive effects.

\section{MATERIALS AND METHODS}

Materials. (-)-Cocaine hydrochloride (Sigma, St. Louis, MO), domperidone, GBR-12909 dihydrochloride, mianserin hydrochloride, $\mathrm{R}(+)-\mathrm{SCH}$ 23390 hydrochloride, S(+)-PD 128907 hydrochloride (Research Biochemicals International, Natick, MA), [ $\left.{ }^{125} \mathrm{I}\right]$ iodosulpride (Amersham, Arlington Heights, IL), $\left[{ }^{125} \mathrm{I}\right] \mathrm{RTI}-121,\left[{ }^{3} \mathrm{H}\right] \mathrm{SCH} 23390$ (DuPont NEN, Boston, MA). Because of poor solubility of GBR-12909 in saline, the drug was dissolved in sterile water using mild heat and sonification and used for intravenous self-administration testing. Cocaine was also dissolved in water for vehicle uniformity. Sterile water served as vehicle control.

Subjects. Male Sprague-Dawley rats (Charles River Laboratories, Wilmington, DE) weighing 350-500 gm were used. Rats were individually housed in a temperature- and humidity-controlled room under a $12 \mathrm{hr}$ light/dark cycle.

\section{Intravenous drug self-administration procedures}

The procedures used for drug self-administration studies have been described previously (Tella, 1995). Briefly, animals were initially trained to press a lever for food pellets in standard operant boxes (Med Associates, East Fairfield, VT) equipped with two levers. Responding on one of the levers resulted in delivery of $45 \mathrm{mg}$ food pellets, whereas responding on the other lever was recorded but had no programmed consequences. Initially, each correct lever-press was reinforced by food delivery. The number of correct lever-presses required to produce a food pellet was gradually increased until stabilized at a response requirement of 10 [10-response fixed ratio (FR10)]. After training, a small plastic pedestal was surgically mounted on the skull using dental cement and stainless steel screws during pentobarbital anesthesia $(55 \mathrm{mg} / \mathrm{kg}$, i.p.). A swivel spring was connected to the plastic pedestal during self-administration sessions. After $7 \mathrm{~d}$ of postoperative recovery, animals were implanted with polyvinyl chloride catheters into femoral veins under halothane anesthesia $(2-3 \%$ in medical grade oxygen). Venous catheters were passed subcutaneously and exited the skin at the midscapular region. Animals were allowed to recover for an additional $7 \mathrm{~d}$ before initiation of intravenous drug self-administration testing. During drug selfadministration sessions, food pellets were no longer delivered, and instead intravenous injections of drug were delivered by way of the catheter, which was connected to an injection pump outside the experimental chamber by polyvinyl tubing. Each completion of 10 lever-press responses (FR10) resulted in a $1 \mathrm{sec}$ intravenous infusion of cocaine $(1 \mathrm{mg} / \mathrm{kg} /$ infusion), GBR-12909 (0.5-1.5 mg/kg/infusion), or sterile water in a volume of 55-110 $\mu \mathrm{l} /$ infusion. There was a $1 \mathrm{~min}$ time-out period, during which the house light was off and responding had no programmed consequences. Experimental sessions were $2 \mathrm{hr}$ in duration and were conducted once daily Monday through Friday. Rats were fed their daily requirement of $\sim 20 \mathrm{gm}(\sim 5 \mathrm{gm} / 100 \mathrm{gm}$ body weight $)$ standard rat chow as a single meal immediately after daily sessions during the study. Patency of each animal's catheter was verified at the end of the last selfadministration session by a rapid intravenous bolus injection of $10 \mathrm{mg} / \mathrm{kg}$ ultrashort-acting barbiturate, methohexital sodium. Animals showing rapid $(\sim 3 \mathrm{sec})$ signs of anesthesia, such as loss of muscle tone, were considered to have patent catheters. All animals used in this study passed this test.

\section{Experiment 1: self-administration of GBR-12909 in cocaine-naive rats}

The objectives of this experiment were (1) to determine whether GBR12909 serves as a reinforcer in drug-naive rats, and (2) to examine the neuroadaptive changes after its chronic limited-access selfadministration. Four groups of four rats each were initially trained to lever-press for food reinforcement. After training, three groups of rats were tested for self-administration of three different doses of GBR-12909 $(0.5,1.0$, or $1.5 \mathrm{mg} / \mathrm{kg} /$ infusion $)$. These doses of GBR-12909 were chosen based on a published report that they are reliably self-administered when substituted for cocaine in cocaine-trained rats (Roberts, 1993). Because animals were shaped with food to lever-press, a fourth group of rats was tested with water placebo to determine the time course for extinction of lever-press responding without food or drug presentations, and this served as a control for GBR-12909 self-administration. Animals were allowed to self-administer GBR-12909 or water for $\sim 6$ weeks. Forty-eight hours after the last session, the water-control group and two groups of rats tested with GBR-12909 (1.0 and $1.5 \mathrm{mg} / \mathrm{kg} /$ infusion) were killed and their brains quickly removed, frozen in isopentane on dry ice, and stored at $-70^{\circ} \mathrm{C}$ until cryostat sectioning. Serial coronal sections (20 $\mu \mathrm{m}$ thick) 
at the level of the striatum were cut at $-20^{\circ} \mathrm{C}$ and thaw-mounted on gelatin-coated glass slides. The slides were stored at $-70^{\circ} \mathrm{C}$ for autoradiography assays. Visual inspection of animals after daily sessions indicated that self-administered GBR-12909 produced motor stimulation that lasted from 3 to $5 \mathrm{hr}$. In view of this, a $48 \mathrm{hr}$ waiting period after the last session seemed adequate for GBR-12909 elimination from the body.

\section{Experiment 2: self-administration of cocaine and the effect of GBR-12909 substitution in cocaine-trained rats}

The objectives of this experiment were (1) to investigate cocaine selfadministration and the resultant neuroadaptive changes after its selfadministration, (2) to determine the effectiveness of GBR-12909 in maintaining self-administration behavior for long periods of time after its substitution for cocaine, and (3) to determine the effect of prolonged substitution of GBR-12909 for cocaine on neuroadaptive changes produced by self-administered cocaine. Four groups of four rats each were initially trained to lever-press for food. After training, three of these four groups had drug injections substituted for food, and they were allowed to self-administer cocaine ( $1 \mathrm{mg} / \mathrm{kg} /$ infusion) during daily test sessions Monday to Friday for $\sim 3$ weeks. The fourth group was not subjected to drug self-administration testing and served as a control group. When cocaine self-administration was stable (not $>20 \%$ deviation from the mean for three consecutive days), either water $(n=3$; one animal died during cocaine self-administration because of pump malfunction) or GBR-12909 $(1 \mathrm{mg} / \mathrm{kg} /$ infusion; $n=4)$ was substituted for cocaine in one group each, whereas the third group $(n=4)$ was allowed to continue to selfadminister cocaine. Because the data from experiment 1 indicated that rats cease to self-administer GBR-12909 after several weeks of testing, all four animals in the GBR-12909-substituted group were monitored daily to determine when each animal ceased to self-administer the drug (that is, when a session occurred where the rat failed to self-administer any injection). One rat ceased responding for GBR-12909 self-administration more rapidly than the others, and this animal was allowed to have access to GBR-12909 for an extended period of time. This rat subsequently responded for GBR-12909 self-administration for $\sim 2$ weeks and then ceased responding again. Twenty four hours after the cessation of responding (i.e., $48 \mathrm{hr}$ after the last GBR-12909 injection), the respective rat was killed by decapitation and its brain rapidly removed, frozen in isopentane on dry ice, and stored frozen at $-70^{\circ} \mathrm{C}$ for cryostat sectioning. Each GBR-12909-tested rat was randomly matched with one rat each from the food-control group, cocaine followed by water selfadministration group, and cocaine self-administration group and thus correspondingly killed at appropriate times. Serial coronal sections (20 $\mu \mathrm{m}$ thick) at striatal and VTA levels were cut at $-20^{\circ} \mathrm{C}$ and thawmounted on gelatin-coated glass slides. The slides were stored at $-70^{\circ} \mathrm{C}$ until used for autoradiography assays.

\section{Experiment 3: self-administration of cocaine after GBR-12909 testing in rats}

The objectives of this experiment were (1) to determine whether prolonged access to GBR-12909 self-administration after its substitution for cocaine in rats alters the reinforcing effects of cocaine when it is subsequently reintroduced, and (2) to study the biochemical consequences of this substitution in comparison with a water-substituted group. Two groups of rats were initially trained for cocaine self-administration for 3 weeks. GBR-12909 (1.0 mg/kg/infusion) was then substituted for cocaine in one group, whereas in the second group, water was substituted for cocaine. Each rat in the GBR-12909 group was monitored daily to determine when it ceased self-administration responding (the rate of responding for GBR-12909 was similar to that of randomly matched water-substituted rat for at least 3 d). When GBR-12909 selfadministration ceased, cocaine was reintroduced for that rat and also for one randomly matched rat in the water-control group. A priming injection of cocaine was given at the start of each session during these subsequent test sessions with cocaine. The time course for restoration of cocaine self-administration behavior in both groups of rats was determined. When cocaine self-administration was restored and had stabilized (not $>20 \%$ deviation from the mean for three consecutive days), GBR12909 or water was again substituted for cocaine in the corresponding rats, and they were tested for an additional 2-4 d. Forty-eight hours after the last session, rats were sacrificed and brains were quickly removed. The right half of each brain was dissected on ice to obtain frontal cortex, hippocampus, caudate putamen $(\mathrm{CPu})$, Acb, hypothalamus, and midbrain regions; these regions were frozen in liquid nitrogen and stored at $-70^{\circ} \mathrm{C}$ until used for HPLC analysis of monoamines and their metabolites. The left half of each brain was frozen in isopentane on dry ice and stored at $-70^{\circ} \mathrm{C}$ until cryostat sectioning. Serial coronal sections ( $20 \mu \mathrm{m}$ thick) at striatal level were cut at $-20^{\circ} \mathrm{C}$ and thaw-mounted on gelatin-coated glass slides. The slides were stored at $-70^{\circ} \mathrm{C}$ for autoradiography assays.

\section{Experiment 4: reacquisition of cocaine and GBR-12909 self- administration after extinction}

The objective of this experiment was to determine whether there are differences in the reacquisition of cocaine versus GBR-12909 selfadministration after extinction of this behavior with water substitution. Because extinction of self-administration behavior with water substitution results in a low level of responding, reacquisition of self-administration responding for the test drug would allow determination of its reinforcing effects uncomplicated by preexisting high levels of responding attributable to food training. Two groups of animals were changed to cocaine self-administration after training to lever-press for food. After $\sim 3$ weeks of cocaine self-administration, water was substituted for cocaine for $10 \mathrm{~d}$ in both groups of rats. After this 10-day extinction test, selfadministration of GBR-12909 (one group) or cocaine (other group) was then tested for $4 \mathrm{~d}$ at a dose of $0.5 \mathrm{mg} / \mathrm{kg}$ /infusion. This sequence of water extinction followed by reacquisition of drug self-administration was repeated with two additional doses of GBR-12909 or cocaine (0.25 and 1.0 $\mathrm{mg} / \mathrm{kg} /$ infusion, respectively). The mean rate of responding during the last $2 \mathrm{~d}$ of each reacquisition testing sequence was calculated. During each reacquisition test session, one priming infusion of the corresponding test drug was given at the start of the session.

\section{Quantitative autoradiography}

$D A$ transporter assay. Slide-mounted sections were incubated for $60 \mathrm{~min}$ at room temperature with $0.07 \mathrm{nM}\left[{ }^{125} \mathrm{I}\right] \mathrm{RTI}-121(2200 \mathrm{Ci} / \mathrm{mmol})$, a highaffinity DA transporter-selective ligand (Boja et al., 1995), in a binding buffer consisting of (in mM): $137 \mathrm{NaCl}, 2.7 \mathrm{KCl}, 10.14 \mathrm{Na}_{2} \mathrm{HPO}_{4}, 1.76$ $\mathrm{KH}_{2} \mathrm{PO}_{4}$, and $10 \mathrm{NaI}$. After incubation, sections were washed twice for 20 min each in ice-cold buffer, followed by a dip in distilled water, and dried under a stream of cool air. Nonspecific binding was determined using 10 $\mu \mathrm{M}$ GBR-12909 hydrochloride.

D1 receptor assay. The buffer solution, $\mathrm{pH} 7.4$, for $\mathrm{D} 1$ assay contained (in $\mathrm{mm}$ ): 50 Tris $\mathrm{HCl}, 120 \mathrm{NaCl}, 5 \mathrm{KCl}, 2 \mathrm{CaCl}_{2}$, and $1 \mathrm{MgCl}_{2}$. Slidemounted sections were preincubated at $25^{\circ} \mathrm{C}$ for $15 \mathrm{~min}$ in buffer. Total binding was determined by incubating sections at $25^{\circ} \mathrm{C}$ for 60 min with buffer solution containing $4 \mathrm{nM}\left[{ }^{3} \mathrm{H}\right] \mathrm{SCH} 23390(81.4 \mathrm{Ci} / \mathrm{mmol})$ and $1 \mu \mathrm{M}$ mianserin (to block $5-\mathrm{HT}_{2}$ receptors). After incubation, sections were washed twice for 5 min with ice-cold buffer, followed by a dip in distilled water, and dried under a stream of cold air. Nonspecific binding was determined with the addition of $10 \mu \mathrm{M}$ unlabeled R(+)-SCH 23390.

D2 receptor assay. The buffer solution, $\mathrm{pH} 7.4$, for $\mathrm{D} 2$ assay contained (in mM): 50 Tris $\mathrm{HCl}, 120 \mathrm{NaCl}, 5 \mathrm{KCl}, 2 \mathrm{CaCl}_{2}$, and $1 \mathrm{MgCl}_{2}$. Slidemounted sections were preincubated at $25^{\circ} \mathrm{C}$ for $15 \mathrm{~min}$ in buffer. Total binding was determined by incubating sections at $25^{\circ} \mathrm{C}$ for $30 \mathrm{~min}$ with buffer solution containing $0.1 \mathrm{nM}\left[{ }^{125} \mathrm{I}\right]$ iodosulpride $(2000 \mathrm{Ci} / \mathrm{mmol})$ and $5 \mathrm{~nm}$ PD128907 (this is approximately five times its affinity value for D3 receptors) (DeMattos et al., 1993) to block D3 receptors. After incubation, sections were washed twice for 5 min with ice-cold buffer, followed by a dip in ice-cold distilled water, and dried under a stream of cold air. Nonspecific binding was determined with the addition of $1 \mu \mathrm{M}$ unlabeled domperidone

Autoradiography and densitometry. Dried sections were apposed to radiosensitive films (Hyperfilm, Amersham) with plastic standards $\left({ }^{125} \mathrm{I}\right.$ labeled microscales, Amersham) for $2 \mathrm{~d}\left(\left[{ }^{125} \mathrm{I}\right] \mathrm{RTI}-121\right.$ and $\left[{ }^{125} \mathrm{I}\right]$ iodosulpride) at $4^{\circ} \mathrm{C}$. For autoradiography of $\left[{ }^{3} \mathrm{H}\right] \mathrm{SCH} 23390$-labeled D1 receptors, dried sections were apposed to tritium-sensitive films (Hyperfilm, Amersham) with plastic tritium standards $\left({ }^{3} \mathrm{H}\right.$-labeled microscales, Amersham) for $7 \mathrm{~d}$ at room temperature. The films were then developed, and ligand-binding was quantified on both sides (one side only for experiment 3) of the brain using a Macintosh computer-based image analysis system (Image, National Institutes of Health) using standard curves generated from the ${ }^{125}$ I-labeled and ${ }^{3} \mathrm{H}$-labeled microscales. Nonspecific binding in these assays did not exceed $10 \%$ of total binding.

\section{Quantitative analysis of monoamines and their metabolites}

Brain regions were analyzed for monoamines and their metabolites using HPLC utilizing electrochemical detection at $+0.75 \mathrm{~V}$ (Andrews and Murphy, 1993). In brief, individual samples were sonicated in 400-500 $\mu 10.1$ $\mathrm{M}$ perchloric acid and centrifuged at $7200 \times g(12,000 \mathrm{rpm})$ for $10 \mathrm{~min}$. 


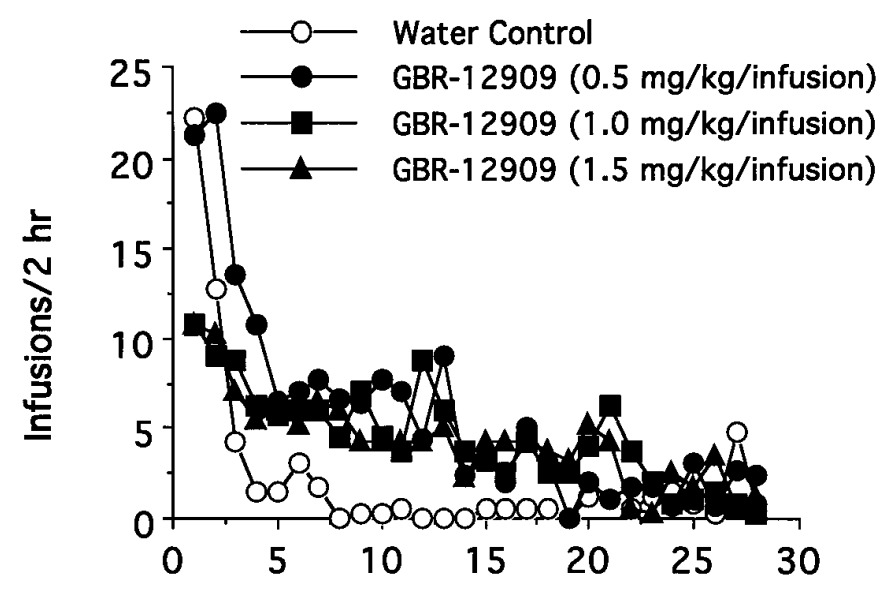

\section{Session Number}

Figure 1. Mean daily rates of intravenous self-administration of GBR12909 and water in drug-naive rats. The data points represent means. There were four animals in each group.

The supernatant $(50 \mu \mathrm{l})$ was injected onto a $10 \mathrm{~cm} \times 4.6 \mathrm{~mm}$ Spherisorb $3 \mu \mathrm{m}$ ODS reverse-phase chromatography column (Thomson Instruments, Springfield, VA) in a mobile phase containing $0.1 \mathrm{M}$ citric acid, $8 \%$ acetonitrile, $0.5 \mathrm{gm} / \mathrm{liter}$ octanesulfonic acid, $0.3 \%$ triethylamine, and 10 $\mu \mathrm{M}$ EDTA at a flow rate of $0.7 \mathrm{ml} / \mathrm{min}$. DA and its metabolites dihydroxyphenylacetic acid (DOPAC) and homovanillic acid (HVA), serotonin (5-HT), 5-hydroxyindoleacetic acid (5-HIAA), and norepinephrine (NE) were separated and detected in a single chromatogram and were quantified as relative peak areas versus the internal standard, 5-hydroxy$\mathrm{N} \omega$-methyltryptamine. The detection limit was $100 \mathrm{pg}$. Protein content was determined by the method of Lowry et al. (1951).

\section{Data analysis}

The behavioral and binding data were analyzed using ANOVA followed by a Fisher's test for determining individual effects or by paired or unpaired $t$ tests, as appropriate. This analysis was performed using Statview computer software.

\section{RESULTS}

\section{Experiment 1: reinforcing and biochemical effects of} GBR-12909 self-administration in naive rats

\section{Reinforcing effects}

Figure 1 shows lever-press responding of rats when responding produced either sterile water or GBR-12909 infusions after food training. Responding of rats in the water-control group decreased markedly within $3 \mathrm{~d}$ and then remained low. In contrast, except for one animal tested with the $0.5 \mathrm{mg} / \mathrm{kg} /$ infusion dose, the three groups of animals self-administering GBR-12909 maintained higher rates of responding than that of the water-control group during the initial few weeks of testing. Average daily intake of GBR-12909 during the second week of testing ranged from 3.2 to $3.8,4.5$ to 7 , and 6.4 to $9.8 \mathrm{mg} / \mathrm{kg}$ in the three groups of rats self-administering the $0.5,1$, and 1.5 $\mathrm{mg} / \mathrm{kg} /$ infusion doses, respectively. As shown in Figure 2, GBR12909 was self-administered at regular intervals within the $2 \mathrm{hr}$ session during the initial weeks; during subsequent weeks of testing, however, there was a marked decline in responding for GBR-12909 (Figs. 1, 2). During the last 2 weeks of testing, there were no significant differences in the number of infusions delivered in the water-control, and the three GBR-12909tested groups of rats (last session: $F_{(3,11)}=0.68, p=0.58$ ). A similar pattern of responding was found when GBR-12909 was first substituted for cocaine in cocaine-trained rats in experi- ments 2 and 3 (see below). Additional statistical analyses of the behavioral data were performed by combining selfadministration data of all three experiments (1-3) for week 2 and experiments 1 and 3 for the last week of GBR-12909 and water testing. These analyses revealed that the GBR-12909 substitution maintained significantly (day $6, p<0.05$; day 7 , $p=0.0001$; day $8, p<0.05$; day $9, p=0.0001$; day $10, p<0.05$ ) higher rates of responding during the second week of testing as compared with the corresponding responding maintained during water substitution. No significant differences were found for the last week of testing between the GBR-12909 and the water-control groups.

\section{Biochemical effects of GBR-12909 self-administration}

Autoradiographic data of $\left[{ }^{125} \mathrm{I}\right] \mathrm{RTI}-121$ binding in $\mathrm{CPu}$ and Acb regions are shown in Figure 3. Self-administration of GBR-12909 (1.0 and $1.5 \mathrm{mg} / \mathrm{kg} /$ infusion) did not alter the $\left[{ }^{125} \mathrm{I}\right] \mathrm{RTI}-121$ binding in either of these regions $\left(\mathrm{CPu}: F_{(2,9)}=0.39, p=0.69\right.$; Acb: $F_{(2,9)}=0.14, p=0.87$ ) (Fig. 3). GBR-12909 self-administration also did not alter $\left[{ }^{125} \mathrm{I}\right]$ iodosulpride and $\left[{ }^{3} \mathrm{H}\right] \mathrm{SCH}-23390$ binding (data not shown).

\section{Experiment 2: reinforcing and biochemical effects of cocaine self-administration and the effect of substituting water or GBR-12909 for cocaine Reinforcing effects}

As shown in Figure 4, before substitution of water or GBR-12909, rats in all groups consistently responded for cocaine $(1 \mathrm{mg} / \mathrm{kg} /$ infusion), and the average daily intake of cocaine during the week before substitution ranged from 17 to $18.3 \mathrm{mg} / \mathrm{kg}$ in the water substitution group and 12 to $13.7 \mathrm{mg} / \mathrm{kg}$ in the GBR-12909 substitution group. The corresponding average daily intake of cocaine in the third cocaine self-administering group ranged from 16.5 to $22 \mathrm{mg} / \mathrm{kg}$. Substitution of water for cocaine led to a rapid decline in responding within 1 week, and responding remained low during the remaining sessions. Results of substitution of GBR-12909 for cocaine were similar to those in experiment 1 ; the animals initially showed regular responding followed by cessation of responding for GBR-12909 self-administration $\sim 6$ weeks after its substitution. Rats allowed continued daily access to cocaine selfadministered cocaine at relatively stable rates and regular intervals until killed (Figs. 2, 4).

\section{Biochemical effects}

There were significant group differences in DA transporter density [CPu: $F_{(3,11)}=5.43, p=0.015$; Acb: $F_{(3,11)}=8.26, p=$ 0.004 ; VTA: $F_{(3,11)}=5.43, p=0.015$; substantia nigra $(\mathrm{SN})$ : $\left.F_{(3,11)}=6.4, p=0.009\right]$. The group of animals that continually self-administered cocaine showed significant increases in $\left[{ }^{125} \mathrm{I}\right] \mathrm{RTI}-121$ binding in $\mathrm{CPu}$, Acb, VTA, and $\mathrm{SN}$ regions compared with the control group of animals (Figs. 5, 6). Water substitution led to a slight recovery of $\left[{ }^{125} \mathrm{I}\right] \mathrm{RTI}-121$ binding toward normal. Unlike water substitution, GBR-12909 substitution led to a complete recovery from increases in $\left[{ }^{125} \mathrm{I}\right] \mathrm{RTI}-$ 121 binding produced by cocaine self-administration in all brain regions (Figs. 5, 6), with there being no significant differences in $\left[{ }^{125} \mathrm{I}\right] \mathrm{RTI}-121$ binding between GBR-12909substituted and control rats.

There were significant group differences in D1 receptor densities in some regions $\left(\mathrm{CPu}: F_{(3,11)}=1.575, p=0.25\right.$; Acb: $F_{(3,11)}=$ $3.62, p=0.049$; SN: $\left.F_{(3,11)}=9.3, p=0.002\right) \cdot\left[{ }^{3} \mathrm{H}\right] \mathrm{SCH}-23390$ binding was intense in the $\mathrm{CPu}, \mathrm{Acb}$, and $\mathrm{SN}$ regions in control 
Figure 2. Event records of GBR-12909, water, and cocaine self-administration in three rats during the 2nd and 6th weeks of GBR-12909 or saline substitution and during the corresponding weeks of cocaine self-administration. Each horizontal line represents one daily $2 \mathrm{hr}$ session. Vertical lines indicate drug injections. Note the regular responding for GBR12909 self-administration during the 2 nd week of the study and the cessation of its self-administration in the same rat during the 6th week of the study. In contrast, the rat self-administering cocaine showed regular responding during both corresponding weeks of testing.
During 2 nd week

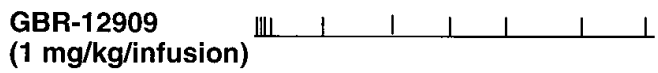

Water

Cocaine (1 $\mathrm{mg} / \mathrm{kg} /$ infusion)

GBR-12909

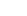

During 6 th week

rats (Fig. 5). $\left[{ }^{3} \mathrm{H}\right] \mathrm{SCH}-23390$ binding in the $\mathrm{CPu}$ and $\mathrm{Acb}$ regions of no-substitution cocaine self-administration rats was not significantly different from that of rats in the control group. In contrast, there was a $20 \%$ increase in D1 receptors in the SN. The substitution of water for cocaine led to a significant increase in $\left[{ }^{3} \mathrm{H}\right] \mathrm{SCH}-23390$ binding in the Acb and $\mathrm{SN}$ as compared with no-substitution cocaine self-administration rats. These changes in the Acb and SN of water-substituted rats corresponded to 20 and $60 \%$ above control values (Fig. 6). GBR-12909-substituted rats showed significant increases in D1 binding in the SN. These increases were of similar magnitude to that observed in the group that received only cocaine.

$\left[{ }^{125} \mathrm{I}\right]$ iodosulpride binding was intense in $\mathrm{CPu}, \mathrm{Acb}$, VTA, and $\mathrm{SN}$. There were no significant changes in D2 receptors in any of the treatment groups (data not shown).

\section{Experiment 3: reinforcing and biochemical effects of cocaine self-administration after GBR-12909 or water substitution}

Reinforcing effects

The effects of substitution of GBR-12909 or water for cocaine were similar to those seen in experiments 1 and 2 . Before substitution, animals in both groups consistently responded for cocaine self-administration, and daily intake during the week before substitution ranged from 18.5 to $21.3 \mathrm{mg} / \mathrm{kg}$ and from

\section{Water Control}

GBR-12909 (1.0 mg/ $\mathrm{kg} /$ infusion)

$\square$ GBR-12909 (1.5 mg/kg/infusion)

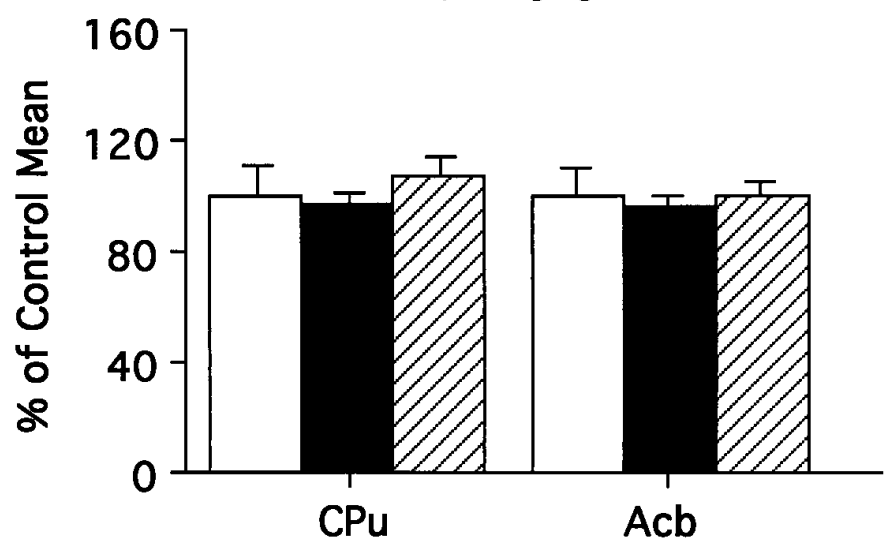

Figure 3. Effect of chronic limited access $(2 \mathrm{hr} / \mathrm{d})$ intravenous selfadministration of GBR-12909 and water on DA transporters. The error bars represent mean \pm SEM of individual values expressed as percent of corresponding mean value of water-control group. There were four animals in each group.
16.4 to $18 \mathrm{mg} / \mathrm{kg}$ for water- and GBR-12909 substitution groups, respectively. After water substitution, there was rapid decline in rates of responding and responding then remained low during subsequent testing, whereas with GBR-12909 substitution, responding was maintained above water-control levels by four of five rats during the initial weeks of testing, followed by a subsequent loss of responding (Fig. 7). When cocaine was again made available in place of water or GBR12909 , there were differences in reacquisition of cocaine selfadministration between these two groups of animals. The animals that had received water substitution showed high rates of self-administration responding on the first day of cocaine access, whereas animals that had received GBR-12909 substitution had a mean delay of $6.6 \pm 1.3$ sessions with a range of two to nine sessions before showing a return of stable rates of cocaine self-administration responding. However, after stabilization of responding for cocaine self-administration, the intake of cocaine was $18.2 \pm 2.1 \mathrm{mg} / \mathrm{kg} 1 \mathrm{~d}$ before a second substitution of GBR-12909, and this was not significantly different from
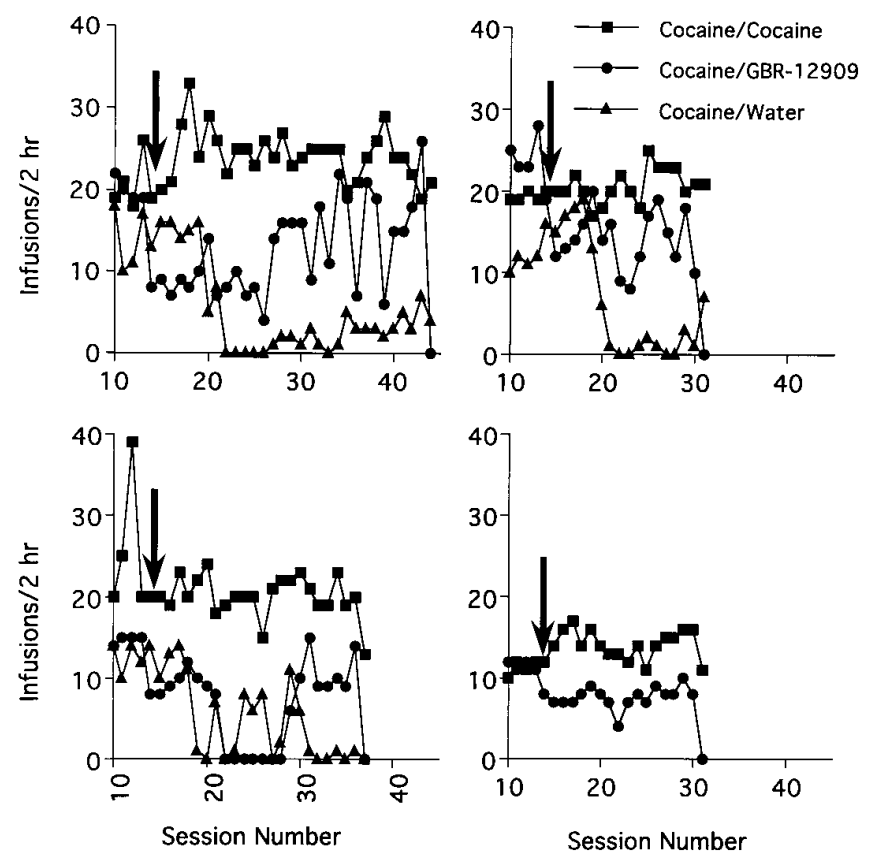

Figure 4. Mean daily rates of intravenous self-administration of GBR$12909(n=4)$ or water $(n=3)$ after their substitution for cocaine in cocaine-trained rats. Each panel shows line graphs of time course data for an individual rat in the GBR-12909 substitution group and for a corresponding rat from the water substitution and cocaine groups. Arrows indicate the session during which substitutions of GBR-12909 or water for cocaine were initiated. 


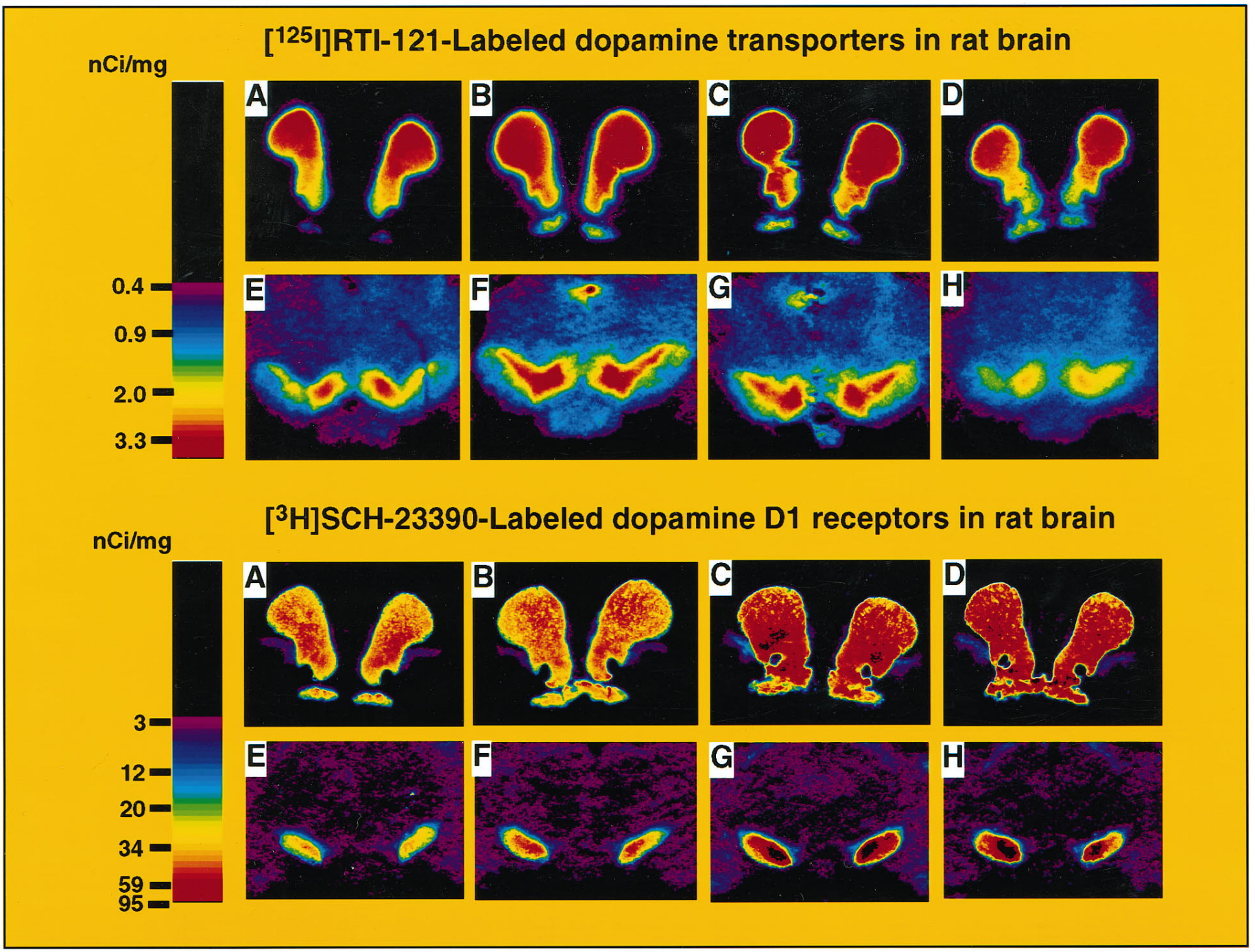

Figure 5. Pseudocolor images of autoradiograms of coronal brain sections labeled with DA transporter-selective ligand [ ${ }^{125}$ I]RTI-121 (top two rows) and D1 receptor-selective ligand $\left[{ }^{3} \mathrm{H}\right] \mathrm{SCH}-23390$ (bottom two rows). $A, E$, Control; $B, F$, cocaine self-administered; $C$, $G$, cocaine self-administered followed by water substitution; $D, H$, cocaine self-administered followed by GBR-12909 substitution. $A-D$ are the sections cut at DA terminal regions, whereas $E-H$ are the sections cut at DA cell body regions.

the corresponding intake before the first substitution of GBR$12909(17.2 \pm 1.4 \mathrm{mg} / \mathrm{kg})$. Similarly, in the water substitution group, there were no significant differences in intake of cocaine on the day before the first $(21.3 \pm 2.9 \mathrm{mg} / \mathrm{kg})$ and second $(21.3 \pm 2.8 \mathrm{mg} / \mathrm{kg})$ substitutions of water. When water or GBR-12909 was substituted for the second time, both groups showed a rapid decline in responding within 1 or $2 \mathrm{~d}$ of substitution. This rapid decline in the rates of responding during the second substitution of GBR-12909 is in contrast to the prolonged testing period required for the loss of responding to take effect after the first substitution of GBR-12909.

\section{Biochemical effects}

$\left[{ }^{125} \mathrm{I}\right] \mathrm{RTI}-121$ binding in $\mathrm{CPu}$ and Acb regions of water-tested groups of rats was significantly greater than that of GBR-12909tested groups (Fig. 8). There were no significant differences between these two groups in the binding of $\left[{ }^{3} \mathrm{H}\right] \mathrm{SCH}-23390$ (Fig. 8) or $\left[{ }^{125} \mathrm{I}\right]$ iodosulpride in the $\mathrm{CPu}$ and $\mathrm{Acb}$ regions (data not shown).

To further evaluate other possible neurochemical bases for the differences in the drug reinforcing profile of water- versus GBR-12909-tested groups of animals, brain monoamine data were also analyzed and are shown in Table 1 . Midbrain DA $(-16 \%)$ and DOPAC $(-34 \%)$ levels and Acb DOPAC $(-20 \%)$ levels in GBR-12909-tested animals were lower than those of water-tested animals. The mean DOPAC/DA ratio in Acb $(0.3 \pm 0.03 ; p<0.05)$ of GBR-12909-tested animals was significantly lower than that of water-tested (Acb: $0.53 \pm 0.09$ ) group. There were no significant differences in 5-HT, 5-HIAA, and HVA in these two brain regions. There were also no significant differences in the contents of DA, 5-HT, and NE and their metabolites levels in $\mathrm{CPu}$, frontal cortex, hippocampus, and hypothalamus of water-tested versus GBR-12909-tested groups (data not shown).

\section{Experiment 4: reacquisition of cocaine and GBR-12909} self-administration after extinction with water

This experiment allowed an assessment of whether consistent responding for GBR-12909 self-administration during the initial weeks of testing in experiments 1-3 was attributable to nonspecific effects of 


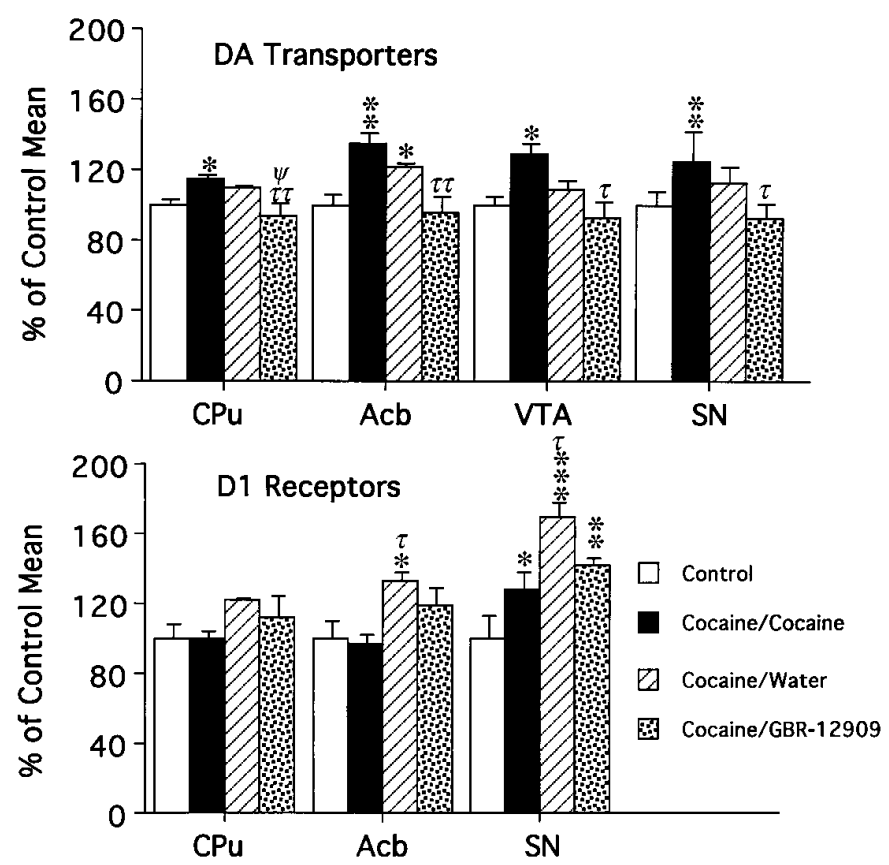

Figure 6. Effects of chronic limited-access $(2 \mathrm{hr} / \mathrm{d})$ intravenous cocaine self-administration $(n=4)$ and substitution of water $(n=3)$ or GBR$12909(n=4)$ for cocaine on DA transporters and D1 receptors. The mean $\left[{ }^{125}\right.$ I]RTI-121 binding in $\mathrm{CPu}, \mathrm{Acb}, \mathrm{VTA}$, and $\mathrm{SN}$ regions of the control group $(n=4)$ were $5.01 \pm 0.12,2.84 \pm 0.15,1.93 \pm 0.09$, and $1.49 \pm 0.11 \mathrm{nCi} / \mathrm{mg}$ tissue, respectively. The mean $\left[{ }^{3} \mathrm{H}\right] \mathrm{SCH}-23390$ binding in $\mathrm{CPu}, \mathrm{Acb}$, and $\mathrm{SN}$ regions of control group $(n=4)$ were $79.3 \pm 6.0$, $75.4 \pm 7.6$, and $38.9 \pm 4.9 \mathrm{nCi} / \mathrm{mg}$ tissue, respectively. The error bars represent mean \pm SEM of individual values expressed as percent of corresponding control group mean. ${ }^{*} p<0.05 ; * * p<0.01 ; * * * p<0.001$ as compared with control group. $\tau p<0.05 ; \tau \tau p<0.01$ as compared with nonsubstituted cocaine self-administered (cocaine/cocaine) group. $\psi p<$ 0.05 as compared with water-substituted cocaine self-administered (cocaine/water) group.

GBR-12909, such as delaying the extinction of lever-press behavior, rather than to true reinforcing effects. During the week before water substitution, the intake of cocaine in the group of animals (range: $16.8 \pm 1.3$ to $19.5 \pm 1.9 \mathrm{mg} / \mathrm{kg}$ ) subsequently tested for GBR-12909 self-administration was similar to that in the group of animals (range: $16.3 \pm 2.4$ to $18.5 \pm 1.3 \mathrm{mg} / \mathrm{kg}$ ) subsequently tested for reacquisition of cocaine self-administration. After extinction with water, cocaine self-administration was reacquired and at doses of 0.5 and $1.0 \mathrm{mg} /$ $\mathrm{kg}$ /infusion; rates of cocaine-maintained responding were significantly higher compared with rates of responding seen previously during water substitution (Fig. 9). Similarly, in the second group, GBR-12909 at a dose of $1.0 \mathrm{mg} / \mathrm{kg} /$ infusion maintained significantly higher rates of responding compared with rates of responding seen previously during water substitution. The lower dose of $0.5 \mathrm{mg} / \mathrm{kg} /$ infusion GBR-12909 showed a tendency $(p=0.063)$ to maintain higher rates of responding compared with water substitution.

\section{DISCUSSION}

\section{Differential reinforcing effects of cocaine versus GBR-12909}

The results of the present study show that the reinforcing effects of cocaine differ from those of GBR-12909. Drug-naive rats readily acquire and subsequently maintain cocaine selfadministration over prolonged periods of time. In contrast, drugnaive rats as well as rats trained previously to self-administer cocaine will self-administer GBR-12909 for few weeks but fail to
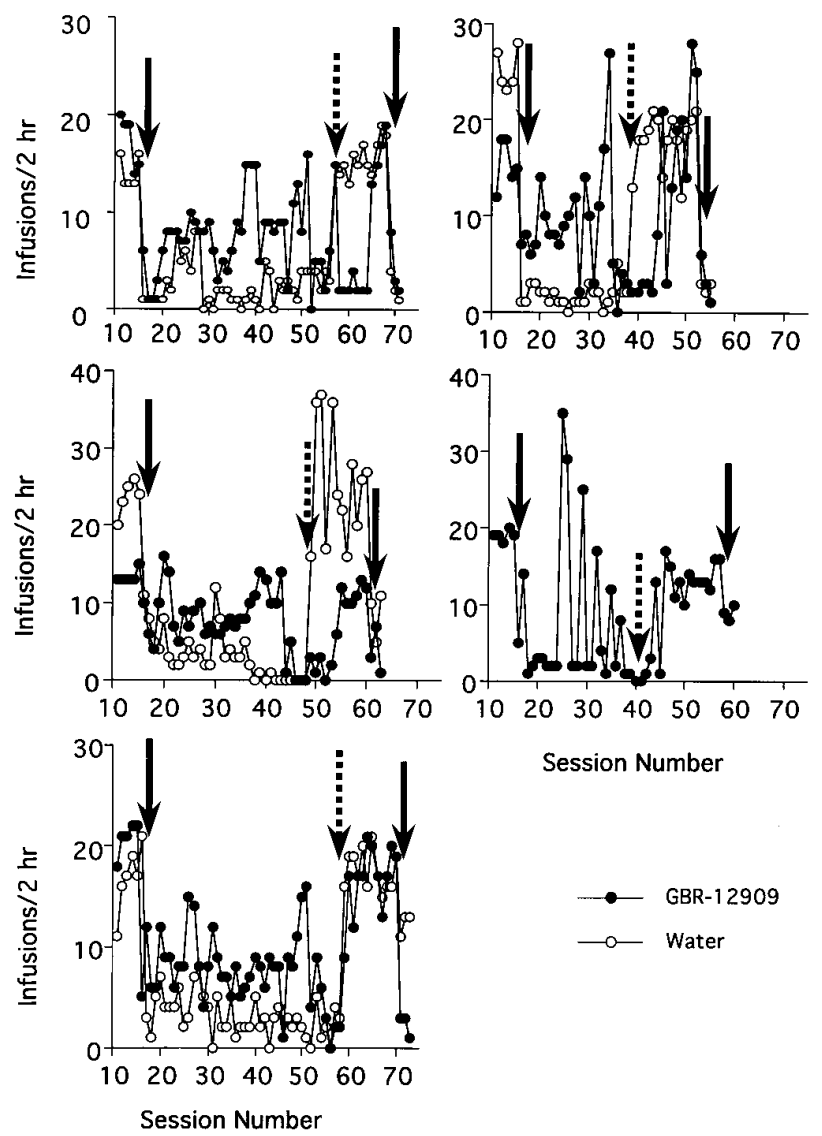

Session Number
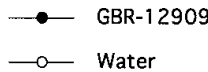

Figure 7. Effects of substitution of GBR-12909 $(n=5)$ or water $(n=4)$ for cocaine in rats trained to self-administer cocaine on subsequent reacquisition of cocaine self-administration. Solid arrows indicate the session during which GBR-12909 or water was substituted for cocaine, whereas broken arrows indicate the session during which cocaine was replaced and reacquisition tests were initiated.

Table 1. The effects of water and GBR-12909 substitution on monoamine levels in cocaine self-administering rats

\begin{tabular}{|c|c|c|c|c|}
\hline Substitution & $\begin{array}{l}\text { Monoamines } \\
\text { and } \\
\text { metabolites }\end{array}$ & Midbrain & Acb & $\mathrm{CPu}$ \\
\hline Water & DA & $2.74 \pm 0.27$ & $63.2 \pm 12.2$ & $85.4 \pm 9.8$ \\
\hline GBR-12909 & DA & $2.31 \pm 0.2^{* *}$ & $64.2 \pm 5.8$ & $85.7 \pm 5.0$ \\
\hline Water & DOPAC & $1.17 \pm 0.17$ & $30.0 \pm 2.6$ & $20.0 \pm 3.4$ \\
\hline GBR-12909 & DOPAC & $0.77 \pm 0.1^{*}$ & $23.9 \pm 2.3^{* * *}$ & $19.6 \pm 1.5$ \\
\hline Water & HVA & ND & $5.03 \pm 0.45$ & $4.89 \pm 0.59$ \\
\hline GBR-12909 & HVA & $\mathrm{ND}$ & $4.88 \pm 0.26$ & $5.36 \pm 0.32$ \\
\hline Water & 5-HT & $6.39 \pm 0.55$ & $3.58 \pm 0.29$ & $3.32 \pm 0.19$ \\
\hline GBR-12909 & 5-HT & $5.99 \pm 0.28$ & $4.13 \pm 0.39$ & $3.19 \pm 0.11$ \\
\hline Water & 5-HIAA & $10.22 \pm 1.04$ & $6.05 \pm 0.30$ & $5.24 \pm 0.30$ \\
\hline GBR-12909 & 5-HIAA & $9.17 \pm 0.58$ & $6.00 \pm 0.37$ & $4.85 \pm 0.21$ \\
\hline
\end{tabular}

The values represent mean \pm SEM (ng/mg protein). There were four water-tested and five GBR-12909-tested animals. ${ }^{*} p=0.06 ;{ }^{*} p<0.05 ;{ }^{*} * * 0.01$ as compared with water-tested group. ND, None detected.

maintain GBR-12909 self-administration with prolonged testing. This loss of self-administration behavior with GBR-12909 does not appear to be attributable to inadequate doses, because similar effects were observed with the three different doses of GBR-12909 used. Moreover, these doses are similar to those used in previous studies in rats (Roberts, 1993). The consistent self-administration 


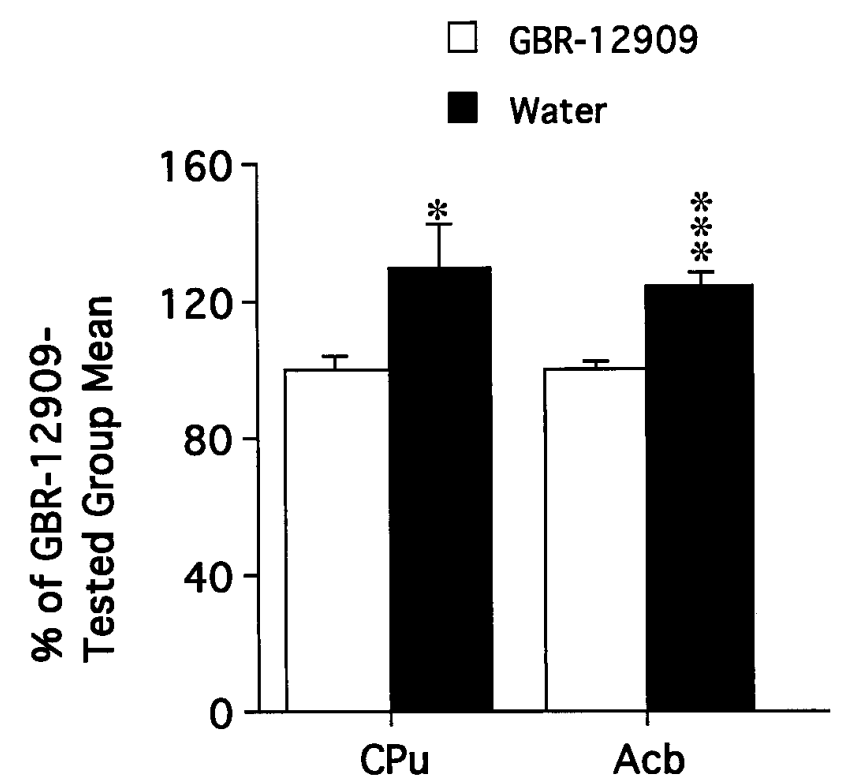

Figure 8. Effect of GBR-12909 $(n=5)$ or water substitution $(n=4)$ on $\mathrm{DA}$ transporters in $\mathrm{CPu}$ and $\mathrm{Acb}$ regions in cocaine-trained rats. The error bars represent mean \pm SEM of individual values expressed as percent of corresponding GBR-12909-substituted group mean. ${ }^{*} p<0.05$; ${ }^{* * *} p<$ 0.001 as compared with GBR-12909-substituted group mean.

of GBR-12909 during the initial weeks of testing in the present experiment is in agreement with previous reports using short-term substitution procedures in rats and monkeys (Bergman et al., 1989; Howell and Byrd, 1991; Roberts, 1993). The novel and important finding of the present study is that this initial consistent responding for GBR-12909 self-administration is subsequently lost during additional weeks of testing. The data in cocaine-trained rats suggest that the previous cocaine exposure did not influence the loss of responding for GBR-12909 self-administration. After extinction of selfadministration behavior during water substitution, animals readily self-administered GBR-12909 on the first day of its access. The similar reacquisition data obtained with cocaine and GBR-12909 suggest that the consistent self-administration responding during the initial weeks of testing with GBR-12909 is not attributable to some nonspecific effect, such as delaying the extinction of lever-press behavior, but rather attributable to a reinforcing effect of GBR12909. Further, when self-administration behavior ceased with prolonged GBR-12909 substitution, animals showed a substantial delay in reacquiring cocaine self-administration and failed to reacquire GBR-12909 self-administration. Glowa et al. (1995) also reported a small delay $(4 \mathrm{~d})$ in the complete reacquisition of cocaine selfadministration after the termination of $12 \mathrm{~d}$ of repeated once daily noncontingent intravenous injections of GBR-12909 in rhesus monkeys. The present findings collectively indicate that with prolonged exposure, GBR-12909 is less reinforcing than cocaine and that previous exposure to GBR-12909 may initially blunt the reinforcing effects of cocaine.

\section{Neurobiological mechanisms underlying the differences in the reinforcing effects of cocaine versus GBR-12909}

Although the binding of both cocaine and GBR-12909 to presynaptic DA transporter sites and the associated increases in synaptic DA triggers their pharmacological responses, the present biochemical data indicate that the long-term biochemical consequences of cocaine are clearly different from those of GBR-12909.
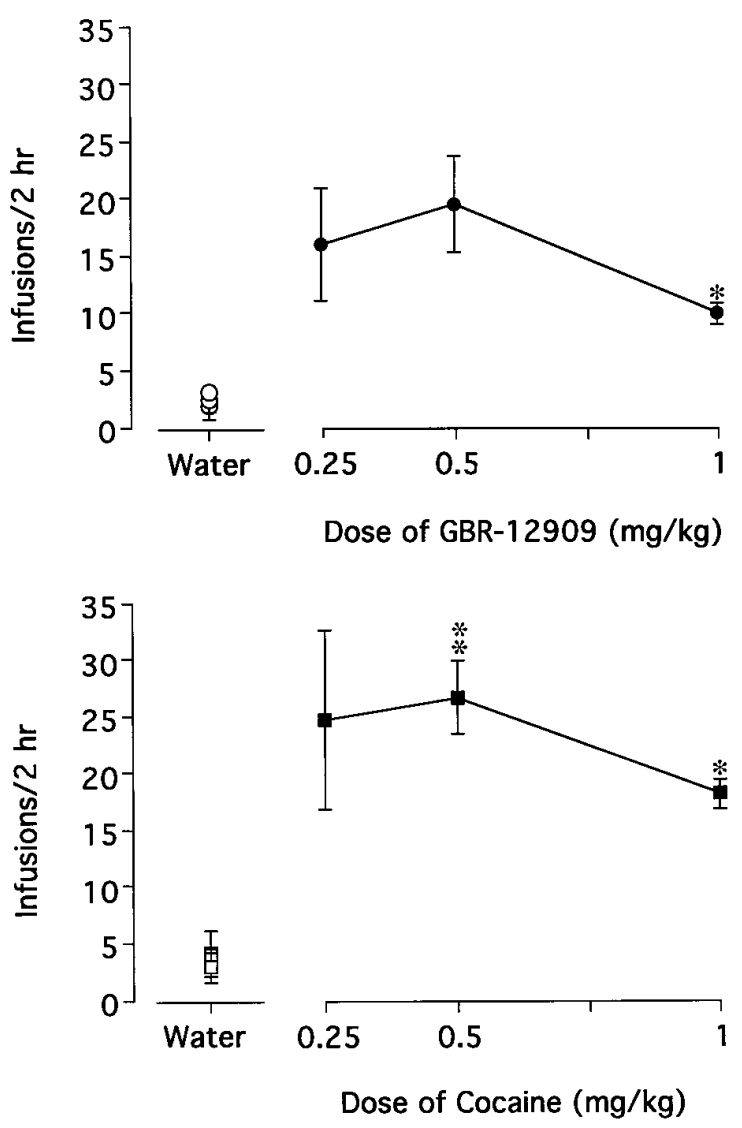

Figure 9. Reacquisition of cocaine $(n=4)$ and GBR-12909 $(n=4)$ self-administration after extinction with water in two groups of rats. Before testing each dose of cocaine or GBR-12909, animals were tested with water for $10 \mathrm{~d}$ to extinguish the behavior. The data points are mean \pm SEM of the last $2 \mathrm{~d}$ of water extinction or reacquisition test. ${ }^{*} p<0.05$; $* * p<0.01$ as compared with the responding obtained with the respective water-extinction test.

A simplified mechanistic scenario for these differences is schematically represented in Figure 10 and is discussed below. The results obtained from the procedure used in the present study show very clearly that cocaine, but not GBR-12909, self-administration leads to the upregulation of DA transporters at the levels of both DA terminals and cell bodies. Moreover, the substitution of GBR12909 for cocaine completely reverses these cocaine-induced increases in DA transporters in all brain regions examined, whereas substitution of water for cocaine only led to a partial reversal (see Fig. 6). Taken together, these results indicate that the reversal of cocaine-associated increases in DA transporters produced by GBR-12909 is not the end product of a natural recovery process consequent to the removal of cocaine, but likely is the result of specific molecular effects of GBR-12909 against cocaine's actions on DA transporters. This also suggests that the interaction of GBR-12909 and cocaine with DA transporters occurs through different mechanisms.

Findings from several previous reports are consistent with our interpretation of the results of the present experiments. (1) In vitro homogenate binding data suggest that cocaine and GBR-12783, an analog of GBR-12909, recognize nonidentical overlapping binding domains on the striatal DA transporter molecule (Refahi-Lyamani et al., 1995). (2) $\left[{ }^{3} \mathrm{H}\right] \mathrm{GBR}=12935$, an analog of GBR-12909 and $\left[{ }^{3} \mathrm{H}\right]$ WIN 35,428, an analog of cocaine, have subregional differences in their binding distribu- 
Figure 10. Schematic representation of a working hypothesis regarding possible biochemical events that occur in dopaminergic systems during limited-access cocaine, GBR-12909 self-administration, and cocaine withdrawal. Cocaine self-administration causes an increase in striatal DA transporters without affecting postsynaptic DA receptors. This increase in DA transporter, which is also seen during cocaine withdrawal, could lead to decreased levels of extracellular DA. This low level of extracellular DA might be responsible for compensatory increase in D1 receptors observed in the cocaine withdrawal state and might be responsible for clinical symptomatology observed in humans during cocaine abstinence. The lack of increase in D1 receptors in cocaine self-administering animals, despite increases in DA transporter density, might be related to the possibility that daily intake of cocaine, which causes repeated increases in extracellular DA, is adequate to counteract this compensatory upregulation of D1 receptors. Similar to cocaine, GBR-12909 selfadministration increases synaptic DA because of its inhibitory action on DA transporter uptake function. However, unlike cocaine, GBR-12909 does not have the ability to upregulate DA transporters. Moreover, prolonged access to GBR-12909 reduces brain DA levels and causes a reversal of cocaine effects on the DA transporters. Thus, although both of these drugs can bind to the DA transporter, the molecular events subsequent to their binding are dissimilar. This suggests that the two drugs may be interacting at different sites on the DA transporter.

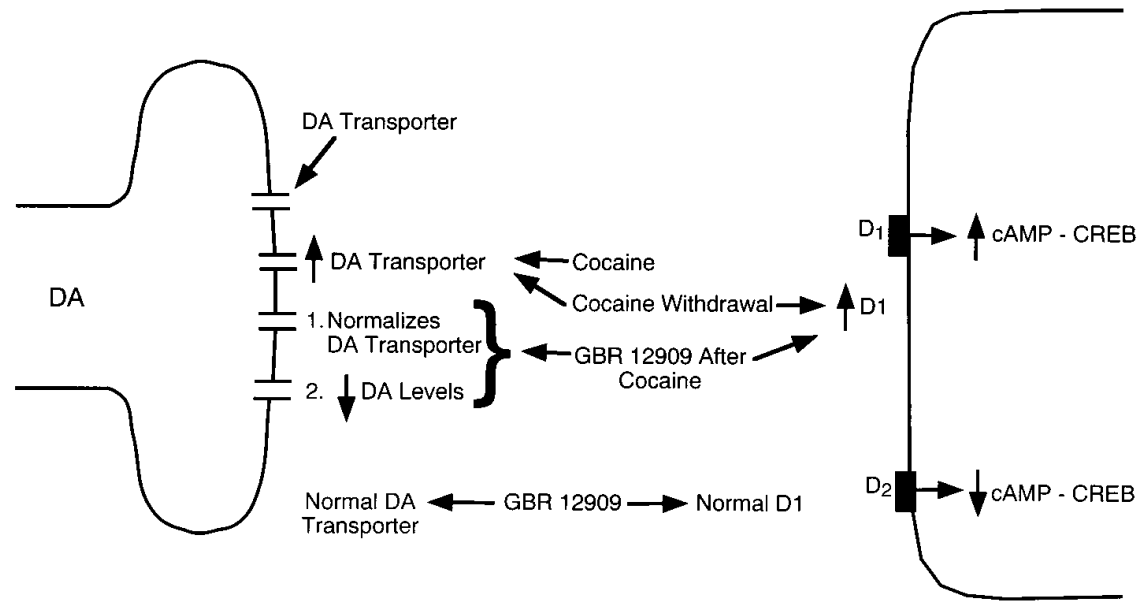

tion in normal rat brain, and the binding of these two ligands are differentially regulated by chronic unlimited access to intravenous cocaine self-administration (Wilson et al., 1994). (3) The destruction of corticostriatal glutamatergic neurons had different effects on the striatal binding of $\left[{ }^{3} \mathrm{H}\right]$ cocaine and [ $\left.{ }^{3} \mathrm{H}\right] \mathrm{GBR}-12935$ (Grilli et al., 1988). (4) GBR-12909 pretreatment antagonizes the increase in extracellular DA produced by intrastriatally infused (Rothman et al., 1991) or systemically administered cocaine (Baumann et al., 1994). (5) GBR-12909 produces only modest elevations in extracellular DA at doses that produce marked stereotypic behavior (Rothman et al., 1991). (6) Cocaine and GBR-12909 produce equivalent locomotor responses at different degrees of occupancy of the DA transporters (Rothman et al., 1992). (7) There is crosstolerance in rats to the discriminative stimulus effects (Katz et al., 1993) and cross-sensitization to the locomotor effects (Elmer et al., 1996) of cocaine to WIN 35428 and RTI-55, two cocaine analogs, but not to GBR-12909. (8) Rats can be trained to discriminate cocaine from GBR-12909 (S. R Tella and S. R. Goldberg, unpublished observations). (9) Cocaine and GBR12909 also differ in their physiological effects (Tella, 1996). It is important to note that in contrast to water substitution, substitution of GBR-12909 after cocaine self-administration caused a selective decrease in both DA and DOPAC levels in the midbrain and of DOPAC in the Acb, whereas the effects of GBR-12909 on DA transporter were more general. The reductions in DA levels after GBR-12909 administration are in contrast to those reported after cocaine administration, which has been reported to cause no significant changes in DA and DOPAC (Kleven et al., 1988; Hurd et al., 1990; Yeh and DeSouza, 1991; Baumann et al., 1993; Alburges et al., 1996). These data further support the idea that cocaine and GBR12909 affect DA systems in different ways. It is possible that
GBR-12909's lack of persistent self-administration might be related to inhibitory effects of GBR-12909 on midbrain DA over extended periods of exposure to its self-administration, resulting in midbrain levels of DA too low to support additional drug self-administration. Because cocaine does not alter brain DA content (Kleven et al., 1988; Hurd et al., 1990; Yeh and DeSouza, 1991; Baumann et al., 1993; Alburges et al., 1996), its continued self-administration over long periods of time would be expected. This interpretation could explain the delayed reacquisition of cocaine self-administration after several weeks of GBR-12909 self-administration, because these animals would presumably have lower levels of midbrain DA. Additional studies on the time course of recovery from the effects of GBR-12909 on DA levels would be important to clarify this interpretation.

The manner in which cocaine causes upregulation of DA transporters and its relationship to the previous discussion is not clear. One possibility is that upregulation of DA transporters might occur in a rheostatic effort to control repeated increases in synaptic DA levels produced by daily sessions of cocaine self-administration (Petit and Justice, 1989; Weiss et al., 1992; Meil et al., 1995; Wise et al., 1995). However, that GBR-12909 also can increase synaptic DA levels (Rothman et al., 1991; Baumann et al., 1994) but did not cause a similar upregulation of DA transporters suggests that such a compensatory mechanism is not very likely. However, the rapid and relatively short-lasting increases in DA produced by cocaine in the synaptic cleft in contrast to the more protracted increases one would expect with GBR-12909 might have triggered different molecular events in the brains of these animals. Another intriguing possibility is that certain binding domains (cocaine binding sites) on the DA transporter are linked to the cascade of adaptive changes in DA transporters, whereas other domains 
(GBR-12909 binding sites) are not. It is nevertheless possible that the dissimilar neuroadaptive response to the two drugs might be secondary to the longer duration of action of GBR12909. For example, Roberts (1993) reported that doses of GBR-12909 with reinforcing efficacies similar to that of cocaine are self-administered at lower rates than cocaine. To test that possibility, we have carried out experiments with DA uptake inhibitors, which like cocaine have relatively rapid kinetics. Our preliminary data show that some of these drugs show upregulation, whereas others do not (S. R. Tella, B. Ladenheim, J. L. Cadet, unpublished observations). Thus, the domain interaction model might be a more important determining factor of neuroadaptive response.

\section{Cocaine withdrawal and $D 1$ receptors}

This is the first demonstration of an increase in D1 receptors during withdrawal after cocaine self-administration. This upregulation of D1 receptors appears to be relatively persistent, because it was observed in animals after water substitution for prolonged periods of time ranging from 4 to 6 weeks. These findings are consistent with the observations that repeated administration of cocaine increases the inhibitory efficacy of dopamine and of D1 receptor agonists on Acb neurons, although it is not clear whether these electrophysiological changes are attributable to an alteration in D1 receptor numbers or to postreceptor intracellular events (Henry and White, 1991, 1995). The increases in D1 receptors might be secondary to the persistent increases in DA transporters observed in these animals during cocaine withdrawal (Fig. 10). Specifically, the increases in DA transporters in these water-substituted cocaine-withdrawn animals might have resulted in lower baseline extracellular DA levels attributable to enhanced reuptake of DA within DA terminals. Thus, D1 receptors may have increased in number to establish a new steady-state level. This interpretation is supported by the reported reductions in extracellular DA during withdrawal after chronic cocaine (Parsons et al., 1991; Robertson et al., 1991; Weiss et al., 1992). The lack of increase in D1 receptors in cocaine self-administering animals, despite increases in DA transporter density in this group, is probably related to the fact that daily cocaine intake would be associated with repeated increases in extracellular DA, increases that would be adequate to prevent any changes in D1 receptors even in the presence of upregulated DA transporters. At a first approximation, this argument does not explain why D1 receptors showed a tendency to increase in the GBR-12909-substituted rats. However, reduced DA content possibly attributable to inhibition of DA synthesis (Nisbrandt et al., 1991) and, more importantly, DA release, might be so significantly altered in the GBR-12909-tested animals that the postsynaptic membranes might be seeing levels of DA that are similar to those encountered in the water-substituted animals. Thus, the end results might be similar, upregulation of D1 receptors, even though the status of DA transporters is different in the water- and GBR-12909-substituted rats.

\section{Clinical and functional implications}

GBR-12909 may have potential for the treatment of cocaine abuse (Rothman and Glowa, 1995). The present findings that chronic substitution of GBR-12909 attenuates the reinforcing effect of cocaine and reverses the effects of cocaine self-administration on DA transporters strengthen the idea of using the drug as a therapeutic agent for cocaine abuse. The observation that the neuroadaptive changes after GBR-12909 self-administration are different from those after cocaine self-administration also supports this notion. The spectrum of behavioral actions and biochemical effects of GBR12909 represents the profile expected from a drug with potential therapeutic effects. However, in light of the previous reports that acute administration of some dopaminergic agonists readily reinstate cocaine self-administration (Wise et al., 1990; Self et al., 1996), similar studies with GBR-12909 are needed to further evaluate its therapeutic potential. The contrasting effects of GBR-12909 and of cocaine on DA transporters suggest that there are critical differences in their molecular mechanisms of action. Additional studies exploring these differences may yield fundamental information about the regulation of the DA transporter molecule. Such information will be critical for the development of therapeutic interventions against cocaine addiction.

\section{REFERENCES}

Alburges ME, Crouch DJ, Andrenyak DM, Wamsley JK (1996) Lack of long-term changes in cocaine and monoamine concentrations in rat CNS following chronic administration of cocaine. Neurochem Int 28:51-57.

Andrews AM, Murphy DL (1993) Sustained depletion of cortical and hippocampal serotonin and norepinephrine but not striatal dopamine by 1 -methyl-4-(2'-aminophenyl)-1,2,3,6-tetrahydropyridine $\left(2^{\prime}-\mathrm{NH}_{2}-\right.$ MPTP): a comparative study with $2^{\prime}-\mathrm{CH}_{3}$-MPTP and MPTP. J Neurochem 60:1167-1170.

Ator NA, Griffiths RR (1992) Differential sensitivity to madozlam discriminative stimulus effects following self-administered versus responseindependent midazolam. Psychopharmacology 110:1-4.

Baumann MH, Raley TJ, Partilla JS, Rothman RB (1993) Biosynthesis of dopamine and serotonin in the rat brain after repeated cocaine injections: a microdissection mapping study. Synapse 14:40-50.

Baumann MH, Char GU, de Costa BR, Rice KC, Rothman RB (1994) GBR12909 attenuates cocaine-induced activation of mesolimbic dopamine neurons in the rat. J Pharmacol Exp Ther 271:1216-1222.

Bergman J, Madras BK, Johnson SE, Spealman RD (1989) Effects of cocaine and related drugs in nonhuman primates. III. Self-administration by squirrel monkeys. J Pharmacol Exp Ther 251:150-155.

Boja JW, Cadet JL, Kopajtic TA, Lever J, Seltzman HH, Wyrick CD, Lewin AH, Abraham P, Carroll FI (1995) Selective labeling of the dopamine transporter by the high affinity ligand $3 \beta$-(4$\left[{ }^{125}\right.$ I]iodophenyl)tropane-2 $\beta$-carboxylic acid isopropyl ester. Mol Pharmacol 47:779-786.

Claye LH, Akunne HC, Davis MD, DeMattos S, Soliman KFA (1995) Behavioral and neurochemical changes in the dopaminergic system after repeated cocaine administration. Mol Neurobiol 11:55-66.

DeMattos SB, Pugsley TA, Shih YS, Whetzel LM, Georgic DH, Van Leeuwen RG, Mackenzie SJ, Smith SA (1993) Identification and characterization of a dopamine D3 selective compound, PD 128907. Soc Neurosci Abstr 19:77.

Deneau G, Yanagita T, Seevers MH (1969) Self-administration of psychoactive substances by the monkey: a measure of psychological dependence. Psychopharmacologia 16:30-48.

Dersch CM, Akunne HC, Partilla JS, Char GU, de Costa BR, Rice KC, Carroll FI, Rothman RB (1994) Studies of the biogenic amine transporters. I. Dopamine reuptake blockers inhibit $\left[{ }^{3} \mathrm{H}\right]$ mazindol binding to the dopamine transporter by a competitive mechanism: preliminary evidence for different binding domains. Neurochem Res 19:201-208.

Dworkin SI, Mirkis S, Smith JE (1995) Response-dependent versus response-independent presentation of cocaine: differences in the lethal effects of the drug. Psychopharmacology 117:262-266.

Elmer GI, Brockington A, Gorelick DA, Carroll FI, Rice KC, Matecka D, Goldberg SR, Rothman RB (1996) Cocaine cross-sensitization to dopamine uptake inhibitors: unique effects of GBR 12909. Pharmacol Biochem Behav 53:911-918.

Ettenberg A, Geist TD (1991) Animal model for investigating the anxiogenic effects of self-administered cocaine. Psychopharmacology 103:455-461.

Farfel GM, Kleven MS, Woolverton WL, Seiden LS, Perry BD (1992) Effects of repeated injections of cocaine on catecholamine receptor 
binding sites, dopamine transporter binding sites and behavior in rhesus monkeys. Brain Res 578:235-243.

Giros B, Wang YM, Suter S, McLeskey SB, Pifl C, Caron MG (1994) Delineation of discrete domains for substrate, cocaine and tricyclic antidepressant interactions using chimeric dopamine-norepinephrine transporters. J Biol Chem 269:15985-15988.

Glowa JR, Wojnicki FHE, Matecka D, Rice KC, Rothman RB (1995) Effects of dopamine reuptake inhibitors on food- and cocainemaintained responding. II. Comparisons with other drugs and repeated administrations. Exp Clin Psychopharmacol 3:232-239.

Goldberg SR, Spealman RD (1982) Maintenance and suppression of behavior by intravenous nicotine injections in squirrel monkeys. Fed Proc 1:216-220.

Griffiths RR, Bigelow GE, Henningfield JE (1980) Similarities in animal and human drug taking behavior. In: Advances in substance abuse: behavioral and biological research (Mello NK, ed) pp 1-90. Greenwich, CT: JAI.

Grilli M, Sanna E, Hanbauer I (1988) Role of corticostriatal nerve projections in the regulation of binding sites for dopamine uptake blockers. Soc Neurosci Abstr 14:929.

Henry DJ, White FJ (1991) Repeated cocaine administration causes persistent enhancement of D1 dopamine receptor sensitivity within the rat nucleus accumbens. J Pharmacol Exp Ther 258:882-890.

Henry DJ, White FJ (1995) The persistence of behavioral sensitization to cocaine parallels enhanced inhibition of nucleus accumbens neurons. J Neurosci 15:6287-6299.

Howell LL, Byrd LD (1991) Characterization of the effects of cocaine and GBR 12909, a dopamine uptake inhibitor, on behavior in the squirrel monkey. J Pharmacol Exp Ther 258:178-185.

Hurd YL, Weiss F, Koob GF, And N-E, Ungerstedt U (1990) Cocaine reinforcement and extracellular dopamine overflow in rat nucleus accumbens: an in vivo microdialysis study. Brain Res 498:199-203.

Izenwasser S, Cox BM (1990) Daily cocaine treatment produces a persistent reduction of $\left[{ }^{3} \mathrm{H}\right]$ dopamine uptake in vitro in rat nucleus accumbens but not in striatum. Brain Res 531:338-341.

Johanson CE, Balster RL (1978) A summary of the results of a drug self-administration study using substitution procedures in rhesus monkeys. Bull Narc 30:43-54.

Johanson CE, Fischman MW (1989) The pharmacology of cocaine related to its abuse. Pharmacol Rev 41:3-52.

Johnson KM, Bergmann JS, Kozikowski AP (1992) Cocaine and dopamine differentially protect $\left[{ }^{3} \mathrm{H}\right]$ mazindol binding sites from alkylation by $N$-ethylmaleimide. Eur J Pharmacol 227:411-415.

Kalivas PW, Stewart J (1991) Dopamine transmission in drug- and stressinduced behavioral sensitization. Brain Res Rev 16:223-244.

Katz JL, Griffiths JW, Sharpe LG, De Souza EB, Witkin JM (1993) Cocaine tolerance and cross-tolerance. J Pharmacol Exp Ther 264:183-192.

King GR, Ellinwood Jr EH, Silvia C, Joyner CM, Xue Z, Caron MG, Lee TH (1994) Withdrawal from continuous or intermittent cocaine administration: changes in D2 receptor function. J Pharmacol Exp Ther 269:743-749.

Kitayama S, Shimada S, Xu H, Markham L, Donovan DM, Uhl GR (1992) Dopamine transporter site-directed mutations differentially alter substrate transport and cocaine binding. Proc Natl Acad Sci USA 89:7782-7785.

Kleven MS, Woolverton WL, Seiden LS (1988) Lack of long-term monoamine depletions following repeated or continuous exposure to cocaine. Brain Res Bull 21:233-237.

Koob GF (1992) Drugs of abuse: anatomy, pharmacology and function of reward pathways. Trends Pharmacol Sci 13:177-184.

Kuhar MJ, Ritz MC, Boja JW (1991) The dopamine hypothesis of the reinforcing properties of cocaine. Trends Neurosci 14:299-302.

Lowry OH, Rosebrough NJ, Farr AL, Randall RJ (1951) Protein measurement with the folin phenol reagent. J Biol Chem 193:265-275.

Meil WM, Roll JM, Grimm JW, Lynch AM, See RE (1995) Tolerancelike attenuation to contingent and noncontingent cocaine-induced elevation of extracellular dopamine in the ventral striatum following 7 days of withdrawal from chronic treatment. Psychopharmacology 118:338-346

Melia KF, Spealman RD (1991) Pharmacological characterization of the discriminative stimulus effects of GBR12909. J Pharmacol Exp Ther 258:626-632.

Nestler EJ (1994) Molecular neurobiology of drug addiction. Neuropsychopharmacology 11:77-87.
Nissbrandt H, Engberg G, Pileblad E (1991) The effects of GBR 12909, a dopamine re-uptake inhibitor, on monoaminergic neurotransmission in rat striatum, limbic forebrain, cortical hemispheres and substantia nigra. Naunyn Schmiedebergs Arch Pharmacol 344:16-28.

Parsons LH, Smith AD, Justice JB Jr (1991) Basal extracellular dopamine is decreased in the rat nucleus accumbens during abstinence from chronic cocaine. Synapse 9:60-65.

Peris J, Boyson SJ, Cass WA, Curella P, Dwoskin LP, Larson G, Lin L-H, Yasuda RP, Zahniser NR (1990) Persistence of neurochemical changes in dopamine systems after repeated cocaine administration. J Pharmacol Exp Ther 253:38-44.

Pettit HO, Justice JB (1989) Dopamine in the nucleus accumbens during cocaine self-administration as studied by in vivo microdialysis. Pharmacol Biochem Behav 34:899-904.

Pilotte NS, Sharpe LG, Kuhar MJ (1994) Withdrawal of repeated intravenous infusions of cocaine persistently reduces binding to dopamine transporters in the nucleus accumbens of Lewis rats. J Pharmacol Exp Ther 269:963-969.

Refahi-Lyamani F, Saadouni S, Costentin J, Bonnet JJ (1995) Interaction of two sulfhydryl reagents with a cation recognition site on the neuronal dopamine carrier evidences small differences between $\left[{ }^{3} \mathrm{H}\right]$ GBR 12783 and $\left[{ }^{3} \mathrm{H}\right]$ cocaine binding sites. Naunyn Schmiedbergs Arch Pharmacol 351:136-145.

Reith MEA, de Costa BR, Rice KC, Jacobson AE (1992) Evidence for mutually exclusive binding of cocaine, BTCP, GBR 12935, and dopamine to the dopamine transporter. Eur J Pharmacol 227:417-425.

Roberts DCS (1993) Self-administration of GBR 12909 on a fixed ratio and progressive ratio schedule in rats. Psychopharmacology 111:202-206.

Robertson MW, Leslie CA, Bennett Jr JP (1991) Apparent synaptic dopamine deficiency induced by withdrawal from chronic cocaine treatment. Brain Res 538:337-339.

Robinson TE, Becker JB (1986) Enduring changes in brain and behavior produced by chronic amphetamine administration: a review and evaluation of animal models of amphetamine psychosis. Brain Res Rev 11:157-198.

Rothman RB, Glowa JR (1995) A review of the effects of dopaminergic agents on humans, animals, and drug-seeking behavior, and its implications for medication development: focus on GBR 12909. Mol Neurobiol 11:1-19.

Rothman RB, Mele A, Reid AA, Akunne HC, Greig N, Thurkauf A, de Costa BR, Rice KC, Pert A (1991) GBR 12909 antagonizes the ability of cocaine to elevate extracellular levels of dopamine. Pharmacol Biochem Behav 40:387-397.

Rothman RB, Greig N, Kim A, de Costa BR, Rice KC, Carroll FI, Pert A (1992) Cocaine and GBR 12909 produce equivalent motoric responses at different occupancy of the dopamine transporter. Pharmacol Biochem Behav 43:1135-1142.

Rothman RB, Cadet JL, Akunne HC, Silverthorn ML, Baumann MH, Carroll FI, Rice KC, de Costa BR, Partilla JS, Wang JB, Uhl G, Glowa JR, Dersch CM (1994) Studies of the biogenic amine transporters. IV. Demonstration of a multiplicity of binding sites in rat caudate membranes for the cocaine analog $\left[{ }^{125} \mathrm{I}\right] \mathrm{RTI}-55$. J Pharmacol Exp Ther 270:296-309.

Self DW, Barnhart WJ, Lehman DA, Nestler EJ (1996) Opposite modulation of cocaine-seeking behavior by $\mathrm{D}_{1}$ - and $\mathrm{D}_{2}$-like dopamine receptor agonists. Science 271:1586-1589.

Sharpe LG, Pilotte NS, Mitchell WM, Dax EM, De Souza EB (1991) Withdrawal of repeated cocaine decreases autoradiographic $\left[{ }^{3} \mathrm{H}\right]$ mazindol-labelling of dopamine transporter in nucleus accumbens. Eur J Pharmacol 203:141-144.

Siegel S (1988) Drug anticipation and drug tolerance. In: The psychopharmacology of addiction (Lader M, ed), pp 73-96. New York: Oxford UP.

Spyraki C, Sealfon SC (1993) Regulation of dopamine D2 receptor mRNA expression in the olfactory tubercle by cocaine. Mol Brain Res 19:313-317.

Tella SR (1995) Effects of monoamine reuptake inhibitors on cocaine self-administration in rats. Pharmacol Biochem Behav 51:687-692.

Tella SR (1996) Possible novel pharmacodynamic action of cocaine: cardiovascular and behavioral evidence. Pharmacol Biochem Behav $54: 343-354$.

Unterwald EM, Ho A, Rubenfeld M, Kreek MJ (1994) Time course of the development of behavioral sensitization and dopamine receptor 
up-regulation during binge cocaine administration. J Pharmacol Exp Ther 270:1387-1397.

Wamsley JR, Alburges ME (1993) Cocaine causes a time dependent and dose dependent increase in D1 receptors and dopamine transporters. Proc West Pharmacol Soc 36:277-282.

Weiss F, Hurd YL, Ungerstedt U, Markou A, Plotsky PM, Koob GF (1992) Neurochemical correlates of cocaine and ethanol selfadministration. Ann NY Acad Sci 654:220-241.

Wilson JM, Nobrega JN, Carroll ME, Niznik HB, Shannak K, Lac ST, Pristupa ZB, Dixon LM, Kish SJ (1994) Heterogenous subregional binding patterns of ${ }^{3} \mathrm{H}$-WIN 35,428 and ${ }^{3} \mathrm{H}$-GBR 12,935 are differentially regulated by chronic cocaine self-administration. J Neurosci 14:2966-2979.

Wise RA, Murray A, Bozarth MA (1990) Bromocriptine selfadministration and bromocriptine-reinstatement of cocaine-trained and heroin-trained lever pressing in rats. Psychopharmacology 100:355-360.

Wise RA, Newton P, Leeb K, Burnette B, Pocock D, Justice Jr JB (1995) Fluctuations in nucleus accumbens dopamine concentration during intravenous cocaine self-administration in rats. Psychopharmacology 120:10-20.

Witkin JM, Nicholos DE, Terry P, Katz JL (1991) Behavioral effects of selective dopaminergic compounds in rats discriminating cocaine injections. J Pharmacol Exp Ther 257:706-713.

Yeh SY, DeSouza EB (1991) Lack of neurochemical evidence for neurotoxic effects of repeated cocaine administration in rats on monoamine neurons. Drug Alcohol Depend 27:51-61.

Yi SJ, Johnson KM (1990) Effects of acute and chronic administration of cocaine on striatal uptake, compartmentalization and release of $\left[{ }^{3} \mathrm{H}\right] \mathrm{do}-$ pamine. Neuropharmacology 29:475-486. 